Canadian

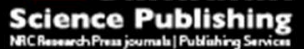

Canadian Journal of Civil Engineering Revue canadienne de génie civil

\title{
Explanation of Tension-side Notch Design Provisions for Glulam in CSA Standard 086-14
}

\begin{tabular}{|r|l|}
\hline Journal: & Canadian Journal of Civil Engineering \\
\hline Manuscript ID & cjce-2015-0088.R2 \\
\hline Danuscript Type: & Article \\
\hline Complete List of Authors: & $\begin{array}{l}\text { Smith, I.; Faculty of Forest and Environmental Management } \\
\text { Meleki Kiwelu, Henry; University of Dar es Salaam, Structural and } \\
\text { Construction Engineering } \\
\text { Weckendorf, Jan; University of New Brunswick, Hybrid Construction } \\
\text { Research Group }\end{array}$ \\
\hline Keyword: & $\begin{array}{l}\text { fracture; fatigue and dam < Engineering Mechanics, structure - wood < }< \\
\text { Struct.Eng. \& Constr.Mate, design < type of paper to review }\end{array}$ \\
\hline & \multicolumn{2}{|c}{} \\
\hline
\end{tabular}

SCHOLARONE ${ }^{1 m}$

Manuscripts 


\title{
Explanation of Tension-side Notch Design Provisions for Glulam in CSA Standard 086-14
}

\author{
Ian Smith (Corresponding author) \\ Professor Emeritus
}

Hybrid Construction Research Group, University of New Brunswick, Fredericton, NB, Canada

\section{Henry Meleki Kiwelu}

Senior Lecturer

Department of Structural and Construction Engineering, University of Dar es Salaam, Dar es Salaam,

\author{
Tanzania \\ Jan Weckendorf \\ Honorary Research Associate
}

Hybrid Construction Research Group, University of New Brunswick, Fredericton, NB, Canada 


\begin{abstract}
Traditionally unreinforced tension-side notches at supports of glued-laminated-timber (glulam) bending members have been designed in Canada assuming shear capacity is reduced in proportion to the square of the residual depth ratio. The origin of that practice lies in World War II era studies in the USA on solid wood members. More recent research in Canada, US and Europe has focussed on application of Linear Elastic Fracture Mechanics (LEFM) methods to such problems, reflecting that such approaches can account for effects that variables other than notch depth ratio. Canadian wood design code CSA Standard 086 “Engineering Design in Wood” first capitalized on availability of LEFM approaches in 1994 by adopting such a method for design of sawn lumber members with tension-side notches at supports. The same was not done then for glulam members because of paucity of supporting test data. That gap has now been filled and the 2014 edition of CSA Standard 086 employs consistent LEFM based design approaches for both sawn lumber and glulam members with tension-side notches. New provisions for glulam recognise influences that notch length and shape, and how laminations in members are fabricated have on member capacities. Discussion here addresses the logic that underpins the new glulam provisions and how application of those provisions impacts design solutions. Overall impact of the new design provisions is to discourage use of relatively large tension-side notches at supports of larger glulam bending members, while not discourage use of notches in smaller glulam members.
\end{abstract}

Keywords: code, design, fracture, glulam, notch, shear, timber 


\section{Introduction}

The Canadian timber design code traditionally assumed that unreinforced tension-side notches reduced shear capacities of glued-laminated-timber (glulam) bending members with rectangular cross-sections proportional to the square of the residual depth ratio $d_{n} / d$, where $d_{n}$ is the notch depth and $d$ the unreduced member depth (CSA 2009, CWC 2010, DeGrace 1986). The logic was that notching creates shear stress concentrations that could causing cracks that might develop in an unstable manner under effects of design level loads. Figure 1 illustrates such a stress concentration predicted by finite element analysis. Limitations were applied that restricted positions of such notches to end of span locations and their depths to not more than $0.25 \mathrm{~d}$. The approach taken in the US is also to assume that shear capacities of members are non-linearly proportional to the residual depth ratio at a tension side notch location, but the proportionality is to the cube of $d_{n} / d$ (APA 2010, ANSI 2012). Other differences are that in the US $d_{n}$ must not exceed $0.1 d$. Also to note is US shear capacities of members of all sizes are taken to be proportional to their cross-section areas, while in Canada that approach may only be taken for members having volumes less than $2.0 \mathrm{~m}^{3}$ (CSA 2009, 2014, ANSI 2012). The Canadian timber design code permits shear design of members of any volume based on comparing total factored loading on a member $\left(W_{f}\right)$ to total factored shear resistance $\left(W_{r}\right) . W_{r}$ is dependent on member volume, member geometry, support arrangement and the configuration of loads. In discussion below the design method applicable to member having volumes less than $2.0 \mathrm{~m}^{3}$ is referred to as normal shear design, and the method applicable to members of any volume as complex shear design. Under the complex method presence of a notch anywhere in member has equal impact on $W_{r}$.

Origins of both Canadian and US traditional design practices for tension-side notched glulam members lie in experiments of World War II vintage on solid wood members undertaken for US military purposes (ANSI 2004). The earliest resulting design code rule was published in the 1944 (NLMA 1944), and remains the foundation of current US practice (ANSI 2012). Why Canadian and US practices diverged has not been discovered by the authors. More recent research in Canada, the US and Europe has focussed 
on using Linear Elastic Fracture Mechanics (LEFM) methods to predict how tension-side notches affect capacities of wood bending members (Murphy 1986, Foliente and McLain 1992, Gustafsson 1988, Larsen and Gustafsson 1989, Riipola 1990, van der Put 1990, Smith and Springer 1993, Smith et al. 1996, Asiz and Smith 2008). Benefit of adopting LEFM methods is they allow effects of variables like notch shape and length to be accounted for, in addition to $d$ and $d_{n}$. The Canadian timber design code CSA Standard 086 “Engineering Design in Wood" was an early adopter of a LEFM based design approach in 1994, but restricted it to design of sawn lumber members with tension-side notches (CSA 1994). Adopting that approach for glulam bending members was considered then but no action taken because of paucity of supporting test data. That data gap has now been filled by Canadian research studies and in consequence a LEFM based design practice for tension-side notched glulam members has been introduced via the 2014 edition of CSA Standard 086 (CSA 2014).

Apart from enabling account to be taken of factors like notch length the new provisions uncouple calculation of the factored shear capacity associated with notch induced fracturing $\left(F_{r}\right)$ from calculation of the factored capacity associated with shear failure ( $V_{r}$ for normal shear design, $W_{r}$ for complex shear design). New provisions also recognise dependence of glulam member resistances to notch induced fracturing on how their laminations are fabricated. A companion paper presents details of research that supports the decisions of CSA Technical Committee 086 (CSA TC086) that led to the new glulam provisions (Weckendorf et al. 2015). Discussion here and in that companion paper addresses glulam members with rectangular cross-sections manufactured accordance to CSA Standard 0122-06 (CSA 2006).

The remainder of this paper elucidates the logic that underpins specific aspects of the new provisions in CSA Standard 086-14 (CSA 2014) for glulam members with tension-side notches at supports, and discusses how their application impacts solutions across a range of design scenarios. All references to tension-side notches imply those located coincident with supports to single or multiple span members. 


\section{Relevant Pre-2014 Provisions}

\subsection{Empirically based glulam provisions}

In the 2009 and earlier editions of CSA Standard 086 provisions relevant to determination of ultimate limiting states for glulam bending members with notches were those falling under Clause 6.5.7 " Shear resistance" (CSA 2009). The underlying presumption irrespective of whether notches were located on tension or compression sides of members was that notching locally alters the shear stress distribution to create a stress concentration(s). As Figure 2 illustrates, further presumptions are that except at notch locations the shear stress distribution is parabolic for a rectangular cross section; and that effects of loads located within one member depth of supports can be neglected during calculation of shear forces for members having volumes less than $2.0 \mathrm{~m}^{3}$. This led to the notion that presence of notches could simply be accounted for by multiplying maximum shear stresses for unreduced cross-sections by amplification terms known as notch factors $\left(K_{N}\right)$. Table 1 summarises the $K_{N}$ applicable to different types of notches.

Two crucial logic flaws are embedded in traditional design code approaches accounting for influences tension-side notches have on capacities of glulam members. Firstly and most importantly, the mechanism by which cracking damage initiates at re-entrant corners of notches is dominated by excessive tension stress in the across the grain direction, results in what is termed opening mode fracturing, Figure 3(a), (Smith et al. 2003, 2007). Consequently any approach that discounts shear capacities of member is incapable of representing how members actually fail. This does not of necessity mean that members with pre-existent large cracks cannot fail due to a dominance of high intensity shear stresses at crack tips (Smith et al. 2003), but equally it has to be considered that code provisions are not intended to apply in such situations. Commentary here applies explicitly to design of new structural members using pre-2014 code editions. The second flaw in the traditional design code approach does not account for the shapes and lengths of notches in a manner analogous to the tradition approach applicable to compression-side notches. In the case of compression-side notches in glulam cracking damage initiates at re-entrant corners 
due dominantly to excessive shear stress in what is termed forward-shearing mode fracturing (Smith et al. 2003), Figure 3(b). This suggests the traditional practice for accounting for effects of compression-side notches has a sounder basis than now past practice in Canada accounting for effects tension-side notches.

A further concern about adequacy of pre-2014 design provisions in CSA Standard 086 related to lack of clear guidance on treatment of common design situations like bird-mouth tension-side notching of inclined glulam members done to create level bearing conditions at upper supports.

\subsection{LEFM based sawn lumber provisions}

LEFM based design of sawn lumber members with tension-side notches was incorporated in CSA Standard 086 in 1994 (CSA 1994) and applies to flat or inclined members, Figure 4. Relevant provisions have remained essentially unaltered since, with clauses 6.5.5.2 "Shear resistance" and 6.5.5.3 "Shear resistance at notch" of the current edition being applicable (CSA 2014). Clause 6.5.5.2 deals with shear capacities of members at locations where cross-section depth has or has not been reduced by notching, while clause 6.5.5.3 addresses ability of members to resist cracking due to stress concentrations at reentrant notch corners. Factored shear resistance $\left(V_{r}\right.$ : clause 6.5.5.2) of a rectangular residual member cross-section lying above a tension-side notch is estimated assuming a parabolic stress distribution, equation (1). Factored fracture shear resistance $\left(F_{r}\right.$ : clause 6.5.5.3) although cast in the form of a shear capacity design calculation is in fact the LEFM calculation of the capacity at which unstable cracking might occur. Within that calculation, equation 2, the material strength parameter specified notch shear force resistance $\left(f_{f}, \mathrm{MPa}\right)$ is actually the square root of the parallel to grain modulus of elasticity multiplied by the critical opening mode energy release rate and divided by member depth (Smith et al. 1996). Notch factor $K_{N}$ from clause 6.5.5.3.2, equation 3 , is the stress intensity factor as developed by Smith and Springer (1993). Pre-2014 both $V_{r}$ and $F_{r}$ were intended to be compared with factored shear forces that are effects of loads acting normal to member axes but neglecting effects of loads located within one member depth of supports. Neglecting effects of loads placed within $d$ of supports has been a 
longstanding approach taken in shear design of structural wood members and is intended to account for favourable departures of shear stress distributions from assumed parabolic distributions at supports (CWC 2010). Figure 5 summarises the logic of the dual factored shear resistance calculations applicable to sawn lumber members (i.e. consideration of $V_{r}$ and $F_{r}$.)

(1) Factored shear resistance: $\quad V_{r}=\phi F_{v} 2 A_{n} K_{Z v} / 3$

(2) Factored fracture shear resistance: $F_{r}=\phi F_{f} A K_{N}$

$$
K_{N}=\left[0.006 d\left\{1.6(1 / \alpha-1)+\eta^{2}\left(1 / \alpha^{3}-1\right)\right\}\right]^{-1 / 2}
$$

where: $A=b d=$ gross cross-section area; $A_{n}=b\left(d-d_{n}\right)=$ net cross-section area; $\alpha=1-d_{n} / d=$ proportional residual cross-section at a notch; $\eta=e / d=$ proportional length of notch; $\phi=0.9=$ resistance factor; and other parameters are as defined in the Appendix. The $f_{f}$ value is always taken to be $0.5 \mathrm{MPa}$ for sawn lumber because CSA TC086 decided refinement was unjustified (Smith et al. 1996).

\section{New (2014) Glulam Provisions}

Section 7.5.7 "Shear resistance" of CSA Standard 086-14 contains all the clause relevant to design of glulam members with tension-side notches at supports (CSA 2014). As with the pre-existing LEFM provisions for sawn lumber members, there now exists the dual requirement to check the adequacy of members to resist shear forces perpendicular to their axes and prevent unstable cracking at re-entrant notch corners. Engineers still have normal (volume $<2.0 \mathrm{~m}^{3}$ ) and complex (any volume) options for checking the adequacy of members to resist shear forces. Equation (4) gives the complex calculation method, and equation (5) the normal calculation method. As previously for members having volumes less than $2.0 \mathrm{~m}^{3}$ it is permitted to neglect effects of loads located with $d$ of member supports when calculating factored shear forces. The traditional limitation that tension-side notches should not reduce depths of glulam members by more than 25 percent has been retained (clauses 7.5.7.4.1 and 7.5.7.4.2).

$$
W_{r}=\phi F_{v} 0.48 A_{g} K_{Z v} C_{V} Z^{0.18} \geq W_{f}
$$

(clause 7.5.7.2(a)) 


$$
\text { Factored shear resistance: } \quad V_{r}=\phi F_{v} 2 A_{g} / 3
$$

where $W_{r}=$ total factored load resistance of member; $A_{g}=b d=$ gross cross-section area; $C_{V}=$ shear load coefficient (clause 7.5.7.5); $Z=$ member volume $\left(\mathrm{m}^{3}\right) ; W_{f}=$ total factored load on member; with other symbols as defined in the Appendix.

Relative the 2009 edition of the code, equations (4) and (5) no longer incorporate notch factor $K_{N}$, due to the already discussed associated flaw in logic. New clause 7.5.7.4.2 deals with calculation of factored fracture shear resistances ( $F_{r}$ values) for glulam members with tension-side notches, with the applicable formula (equation 6) for factored fracture shear resistance $F_{r}$ of glulam matching technically that for sawn lumber (equation 2), and with $K_{N}$ given by equation (3). The only difference between equations (2) and (6) is that the former uses $A$ and the latter $A_{g}$ to denote gross cross-section area. As stated in clause 7.5.7.1.2, effect of all loads acting on a member must be taken into account when estimating the factored shear force. In the case of members with volumes $<2.0 \mathrm{~m}^{3}$ this was implemented to account for research that showed that it is not correct to neglect such loads when fracture capacity calculations for notched members are uncoupled from shear capacity calculations (Weckendorf et al. 2015).

(6) Factored fracture shear resistance: $F_{r}=\phi F_{f} A_{g} K_{N}$

(clause 7.5.7.4.2)

For glulam the factored notch shear strength $F_{f}$ (equation 7) calculated using specified shear strength $f_{f}$ (equation 8) and the moisture service condition related modification factor $K_{S t p}$. A variable value of $f_{f}$, is used because full-size glulam member tests revealed it should depends on the effective lamination width $b_{\text {eff }}$ as reported by Weckendorf et al. (2015).

(7) Factored notch shear strength: $\quad F_{f}=f_{f}\left(K_{D} K_{H} K_{S t p} K_{T}\right)$

(8) Specified notch shear strength: $f_{f}=2.5 b_{e f f}^{-0.2} \quad(\mathrm{MPa})$ (clause 7.5.7.4.2) 
where: $K_{S t p}=$ moisture related service modification factor $=1.00$ for dry service, and 0.85 for wet service conditions; $b_{\text {eff }}=$ effective laminate width $=$ beam width (i.e. cross-section thickness) for single-piece laminations, or width of the widest piece for multiple-piece laminations; with other symbols as defined in the Appendix. Numerically the values match those for $K_{S t p}$ applicable to tension perpendicular to grain (Table 7.4 .2 of the code).

New clause 7.5.7.4.1 "Longitudinal shear resistance of residual member above notch" allows presence of notches of limited length to be ignored. In this specific instance limited length means that the nearest reentrant corners of notches are located not more than $d$ from the edges of nearest supports. That relaxation recognizes that small notches create shear stress distributions in residual portions of members above notches that are not parabolic. CSA TC086 took account of detailed finite element analyses by the authors like those illustrated in Figures 6(a) and 6(b) when establishing clause 7.5.7.4.1. The same is not true for members with longer tension-side notches at supports, because in such instances shear stresses in residual cross-sections of members can approach a parabolic distribution as Figure 6(c) illustrates. However, when the proportional length of a notch $(\eta=e / d)$ is greater than 1.0 the stress concentrating effects of notches is always strong enough to preclude shear failure governing instead of cracking at the notch. This is why factored shear resistance $V_{r}$ (equation 5) need always only calculated using the gross cross-section area. To note is absolute values of von Mises stresses in Figure 6 do not indicate which location in a member will actually govern its capacity, because there is not a direct relationship of those to critical stress levels for anisotropic material like glulam (Smith et al. 2003).

\section{Impact of 2014 Changes for Glulam}

Discussion here addresses how alteration of code provisions in the 2014 edition of CSA Standard 086 impacts total factored load $\left(W_{f}\right)$ capacities of notched Spruce-Lodgepole Pine-Jack Pine 20f-E glulam members. The specified shear strength $f_{v}$ is $1.75 \mathrm{MPa}$ for such members at reference design conditions 
(i.e. $K_{D}=K_{H}=K_{S v}=K_{S t p}=K_{T}=1.0$ ). Assessments are based on $W_{f}$ rather than factored shear resistances because the former is the truest reflection are how design solution have altered.

\subsection{Simple shear design method: volume $<2.0 \mathrm{~m}^{3}$}

\subsubsection{Neglecting presence of small notches}

Design solutions in Table 2 illustrate impacts of new clause 7.5.7.4.1 for inclined members with a shallow bird-mouth notches at the upper support, for cases where some load is located less than $d$ from the upper support (Arrangement A, Figure 7(a)) and cases where all load is located at least $d$ from the upper support (Arrangements B, Figure 7(b)). Because the bird-mouth notch is short and shallow, i.e. not exceeding $0.25 d$ deep; $\leq d$ from the inner edge of the closest support to the farthest edge of the notch, its presence can be ignored. As tabulated results demonstrate, there can be significantly increase in the $W_{f}$ that can be applied to a member with Arrangement B simply because the presence of the notch that previously controlled $V_{r}$ no longer has to be considered. On the other hand, Arrangement A illustrates situations where new provisions can lead to either reductions or increases in $W_{f}$. In the particular instance considered $W_{f}$ is the lesser of $2.0 V_{r}$ or $1.5 F_{r}$ and when $d_{n}$ is greater than $0.1 d, V_{r}$ can govern $W_{f}$. Also to

consider is because specified notch shear force resistance $f_{f}$ is proportional to $b_{\text {eff }}{ }^{-0.2}$ (clause 7.5.7.4.2) the ratio $V_{r} / F_{r}$ does not depend solely on notch size and member geometry. In consequence it is hard to generalise statements about which ultimate limiting state mechanism will govern for specific member geometries and load arrangements. However in many instances solutions have not changed greatly between 2009 and 2014 editions of the code.

\subsubsection{Separating calculation of effects of notches from calculation of $V_{r}$}

Here the impact of separately determining the factored shear resistance $V_{r}$ and factored notch shear resistance $F_{r}$ is assessed by comparing the ratio of $F_{r, 086-14}(\mathrm{CSA} 2014)$ to $V_{r, 086-09}(\mathrm{CSA} 2009)$, using equation (9). Equation (9) ignores possible concurrent impacts of new clause 7.5.7.1.2 and 7.5.7.4.1 and 
situations where shear resistances of cross-sections not coincident with tension-side notches govern solutions. With these caveats the equation yields a widely valid understanding of impact that introducing a LEFM based calculation method has on design solutions.

$$
\begin{aligned}
F_{r, 086-14} / V_{r, 086-09} & =\phi 3 F_{f} A_{g} K_{N, 086-14} / \phi 2 F_{v} A_{g} K_{N, 086-09}=3 F_{f} K_{N, 086-14} / 2 F_{v} K_{N, 086-09} \\
& =3.75 b_{e f f}^{-0.2} K_{D} K_{H} K_{S v} K_{S t p} K_{N, 086-14} / F_{v}\left(1-d_{n} / d\right)^{2} \leq 1 / K_{N, 086-09}
\end{aligned}
$$

Substituting for $F_{f}=1.75 \mathrm{MPa}, K_{\mathrm{N} .086-14}$ and $K_{\mathrm{N} .086-09}$, and rearranging equation (9) becomes:

$$
F_{r, 086-14} / V_{r, 086-09}=C_{d} C_{\alpha} C_{b_{-} \text {eff }} C_{\text {notch-shape }} \leq 1 / \alpha^{2}
$$

where $C_{d}=27.664 d^{-0.5}, C_{\alpha}=\alpha^{-2}, C_{b_{-} \text {eff }}=b_{\text {eff }}^{-0.2}, C_{\text {notch-shape }}=\left(1.6(1 / \alpha-1)+\eta^{2}\left(1 / \alpha^{3}-1\right)\right)^{-0.5}$.

As equation (10) demonstrates, impacts of new provisions are proportional to the inverse of the square root of $d$, the inverse of the square of residual depth ratio $\alpha^{2}=\left(1-d_{n} / d\right)^{2}$, the inverse of the fifth root of $b_{\text {eff, }}$ and the inverse of a composite parameter that accounts for notch shape (i.e. combined effects of $\alpha$ and $\eta=e / d$ ). Consequently the strongest influences on the ratio $F_{r, 086-14} / V_{r, 086-09}$ are the cross-section depth $d$ and the residual depth ratio $\alpha$. Increases in $d$ and $\alpha$ both reduce the ratio $F_{r, 086-14} / V_{r, 086-09}$. Assigning values $\alpha,=0.9, \eta=0.2$ and $b_{e f f}=80 \mathrm{~mm}$ leads to the specific case $F_{r, 086-14} / V_{r, 086-09}=32.39 d^{-0.5} \leq 1.56$ has the corollary $F_{r, 086-14}=V_{r, 086-09}$ when $d=1049 \mathrm{~mm}$. Figure 8 shows how variations in $\alpha, b_{\text {eff }}$ and $d$ impact $F_{r \text {, }}$ ${ }_{086-14} / V_{r, 086-09}$ relative to index values of $0.9,80 \mathrm{~mm}$ and $1049 \mathrm{~mm}$ respectively. The broad conclusion that can be drawn from Figure 8(a) is that incremental variations in cross-section depth only have strong influence gradients when $d$ is less than about $800 \mathrm{~mm}$, meaning that new design provisions most strongly alter solutions for low-profile members. What Figure 8(b) shows is that using the notch factor $K_{N, 086-14}$ involves a much different dependence of design solutions on the residual depth ration $\alpha$ than was assumed previously via adoption of $K_{N, 086-09}$. By extension it can be concludes that in general when presence of tension-side notch at a support governed design solutions under pre-2014 provisions the solutions tended to be conservative when the $\alpha$ values lay toward the minimum allowed value of 0.75 , and unconservative when $\alpha$ values lay toward the upper limit of 1.0 (i.e. shallow notches). This statement is supported by test evidence (Weckendorf et al. 2015). Figure 8(c) shows that the influences gradient for $C_{b_{-} \text {eff }}$ is greatest when $b_{\text {eff }}$ is small. The impact of the new code provisions is therefore to provide incentive to minimise 
$b_{\text {eff }}$ in situations where factored notch shear resistance $F_{r}$ governs design solutions. Because previously design code provisions did not recognise that how laminations are constructed in their widths influences shear controlled failure mechanisms, engineers now have a way of specifying glulam layups that maximise capacities without changing the species, grade or member dimensions.

How combinations of $\alpha$ and $\eta$ alter notch shape influence coefficient $C_{\text {notch-shape }}$ is illustrated in Table 3 . The broad deduction to be drawn from tabulated $C_{\text {notch-shape }}$ is making notches that are long relative to their depths results in strong design penalties under 2014 code provisions; which is consistent with experimental and fracture mechanics analyses (Smith and Springer 1993, Smith et al. 2003). Table 4 shows the values of $C_{\text {notch-shape }}$ below which $F_{r, 086-14}$ is less than $V_{r, 086-09}$, with the tabulated values corresponding to when equality exists between $F_{r, 086-14}$ and $V_{r, 086-09}$ for various combinations of $d$ and $b_{\text {eff. }}$. Comparing $C_{\text {notch-shape }}$ values in Tables 3 and 4 shows the new design code provisions are especially liberal when $b_{\text {eff }}$ and $\eta(=e / d)$ are small. However, it should be borne in mind that the ratio $V_{r, 086-14} / V_{r, 086-09}$ is $1 / \alpha^{2}$ when notch lengths are small and therefore the discussion of $F_{r, 086-14} / V_{r, 086-09}$ here does not relate to cases where the presence of notch can now be ignores (Section 4.1.1).

\subsection{Complex shear design method: all volumes}

Discussion here focusses on design of members having volumes greater than $2.0 \mathrm{~m}^{3}$ and impacts of separately considering total factored load resistance $W_{r}$ (clause 7.5.7.2; equation 4) and factored fracture shear resistance $F_{r}$ (clause 7.5.7.4.2; equation 6).

\subsubsection{Single-span members with symmetric loads}

The example used to illustrate impacts new code provisions have for single-span members with symmetrical loads is beams with simple supports and full-length uniformly distributed load, $C_{v}=3.69$ 
(Table 7.5.7.5B, CSA 2014). Table 5 compares values of total factored load $W_{f}$ (taken to equal $W_{r}$ ) that are allowed by 2014 and 2009 editions of the code for a tension-side notch $\left(d_{n} / d=0.15, e / d=0.15\right)$ at one or both supports. Tabulated $W_{f}$ values in cell shaded grey represent situations not likely to occur in practice (i.e. other failure mechanisms would usually governing at lower span to depth ratios than those associated with chosen design volumes). Such cases are included solely to indicate conceptual impacts of new provisions. It is readily apparent that adopting a LEFM based method for determining when fracturing at tension-side notches will control design capacities can lower design capacities considerably. This is only the case however when member volumes are large, span to depth ratios are small, and notches are deep and/or long. Conversely in other situations capacities increase significantly under the new provisions, even if member volumes are large and span to depth ratios small. New provisions militate against poor design choices when single span members are notched.

\subsubsection{Single-span members with non-symmetric loads}

The example used to illustrate impacts new code provisions have for single-span members with nonsymmetrical loads is beams with simple supports and triangular load of zero value at one end and maximum value at the other end, $C_{v}=3.40$ (Table 7.5.7.5B, CSA 2014). Table 6 compares values of $W_{f}$ values for members having a tension-side notch $\left(d_{n} / d=0.15, e / d=0.15\right)$ located at the end support corresponding to zero or maximum load. Again $W_{f}$ values in grey shaded table cells indicate situations that facilitate conceptual understanding of impacts.

Results in Table 6 speak directly to the basic irrationality of the pre-2014 design provision that assigned the same design capacity to members irrespective of at how notch positions related to the loading arrangement. The new provisions introduce the rational requirement that the fracture capacity at a notched location can govern only if it corresponds to a high shear force location. As for symmetrically loaded single span members, adopting a rational LEFM based method to determine when fracturing at notches 
will control design capacities can lower design capacities considerably. This is so when members volumes are large and span to depth ratios are small; but only if tension-side notches are coincident with the support at which the shear force is maximum. In situations where notches are coincident with the support at which the shear force is minimum new code provisions can increased member capacities substantially.

\subsubsection{Multiple-span members}

The example used to illustrate impacts new code provisions have for multiple-span glulam members is symmetric two-span beans with a full-length uniformly distributed load, $C_{v}=6.66$ (Table 7.5.7.5D, CSA 2014). Table 6 compares $W_{f}$ values for members having a range of volumes and cross-section dimensions $\left(d_{n} / d=0.15, e / d=0.15\right)$. Once more values in grey shaded table cells indicate situations that aid conceptual appreciation of impacts. As with non-symmetric loading on single span members, it is clear that pre-2014 design provisions were not rational in the sense that the same design capacity was assigned to members irrespective of the support at which a tension side notch was located. In essence the 2014 design provisions impose a penalty relative to previous permitted design capacities in situations where designers choose to located relatively deep and/or long tension-side notches coincident with interior support positions of large multiple-span glulam members. New provisions can result in increased design capacities for multiple-span members having tension-side notches coincident with end supports positions. Overall design outcomes resulting from application of the 2014 design provisions are rational irrespective of the number of spans continuous members have.

\section{Future Possibilities}

Option that exist for future change of notched glulam members design provisions in CSA Standard 086 include: 
1. Removal of the requirement that notch depth ratio $\left(d_{n} / d\right)$ not exceed 0.25 for tension-side notches. This is possible because the underlying theory associated with calculation of factored notch shear force resistances ( $F_{r}$ values) applies to any value of $d_{n} / d$ (Smith and Springer 1993). Eurocode 5 which also uses a LEFM based design method to account for effects notches places no restriction on ratio $d_{n} / d$ (CEN 2004). Also to note is the parallel European design method distinguishes between cases where flat members have square cut or inclined notch faces, Figure $4 \mathrm{a}$ versus $4 \mathrm{~b}$. The philosophy followed in Canada is that inclining faces of notches in flat members only temporarily increases capacities of members, because when members enter service any drying leads to some cracking irrespective of the angle of the re-entrant corner. That hypothesis should be verified.

2. Adopting a consistent approach for design of members having compression-side and tension-side notches. This is possible because the theory that underpins derivation of notch factor $\left(K_{N}\right.$ values $)$ is the same in both cases (Smith and Springer 1993, Smith et al. 2003). The difference in application would be that for compression-side notches the specified notch shear strength $\left(f_{f}\right)$ would be based on the forward-shearing mode fracture energy release rate of glulam rather than its opening mode fracture energy release rate. The $f_{f}$ for compression-side notches would be about three times values for tension-side notches (Smith et al. 2003).

3. Inclusion of design provisions applicable to notches reinforced in various ways, including localised surface reinforcement of members and members locally toughened using fasteners like self-tapping screws. Relevant research has already been completed in Europe (Jockwer 2014).

4. Removal of the complex method of calculating shear controlled capacities of glulam members (i.e. calculation of $W_{r}$ ). Arguments supporting consideration of this include that all other wood design codes employ only the normal shear design method irrespective of member volumes (e.g. ANSI 2012, CEN 2004). 
5. Increasing magnitudes of specified shear strengths ( $f_{v}$ values). Recently recalibrated US reference shear strengths assigned to comparable species and grades of glulam are equivalent to about twice present Canadian $f_{v}$ values (ANSI 2012), but with a reduction factor of 0.72 applicable if members do not have prismatic cross-sections and/or contain notches. The difference stems from US values being based on full-size member tests data rather than on small-scale shear specimen data, which is still the basis in Canada (Yeh and Williamson 2001).

\section{Conclusions}

New provisions in CSA Standard 086 have put design capacities of unreinforced glulam members that might fracture at tension-side notches on a rational basis, by using Linear Elastic Fracture Mechanics methods. In some instance impact of the change is member load capacities controlled by presence of tension-side notches at supports are increased, while in other cases member load capacities are significantly reduced. Increased capacities are mostly associated with relatively small notches in small

glulam members, and decreased capacities are mostly associated with relatively large notches at locations coincident with high shear forces in large glulam members. New provisions also address anomalies that existed in design solutions obtained by the 'complex shear design method' that inversely relates shear strength to member volume. There is now consistency in the how notched members made from sawn lumber and glulam are designed, with potential existing to also apply the same approach to members locally reinforced at notches. Seen through the prism of good structural engineering practice, overall impact of the new design provisions in CSA Standard 086 is to discourage use of relatively large tensionside notches at supports of larger glulam bending members, while not discourage use of notches in smaller glulam members.

\section{Acknowledgements}


Funding was provided by the Canadian Natural Sciences and Engineering Research Council under Discovery and Engage grants held by Professor Smith. Comments on the draft manuscript from Dr. Borjen Yeh, Director, Technical Services Division, APA-The Engineered Wood Association, Tacoma, WA are greatly appreciated.

\section{APPENDIX: Notation}

$A=A_{g}=b d=$ gross cross-section area

$A_{n}=b\left(d-d_{n}\right)=$ net cross-section area

$b \quad=$ member thickness

$b_{\text {eff }} \quad=$ effective laminate width

$d \quad=$ member depth

$C_{b_{-} e f f}=$ influence coefficient for effective laminate width $=2.4022 b_{e f f}^{-0.2}$

$C_{d}=$ influence coefficient for cross-section depth $=32.388 d^{-0.5}$

$C_{n o t c h-s h a p e}=$ influence coefficient for notch shape $=2.2783\left\{1.6(1 / \alpha-1)+\eta^{2}\left(1 / \alpha^{3}-1\right)\right\}^{-0.5}$

$C_{\alpha}=$ influence coefficient for residual cross-section depth $=0.81 / \alpha^{2}$

$d_{n}=$ notch depth

$e \quad=$ notch length

$f_{f} \quad=$ specified notch shear strength

$f_{v}=$ specified shear strength

$F_{r}=\phi F_{f} A_{g} K_{N}=$ factored notch shear force resistance

$F_{f}=f_{f}\left(K_{D} K_{H} K_{S t p} K_{T}\right)=$ factored notch shear strength

$F_{v}=f_{v}\left(K_{D} K_{H} K_{S t p} K_{T}\right)=$ factored shear strength

$K_{D}, K_{H}, K_{S f}, K_{S t p}, K_{S v}, K_{T}=$ service situation related modification factors (adjust $f_{v}$ and $f_{f}$ values from those applicable to reference conditions to ones applicable to design service situations, i.e. for duration of the loading, system behaviour, moisture conditions and chemical treatment) 
$K_{N}=$ notch factor

$K_{Z v}=$ size factor in shear

$Q_{x}=$ member shear force at length coordinate $x$

$W_{f}=$ total factored load on member

$W_{r}=$ total factored load resistance of member

$\alpha=1-d_{n} / d=$ proportional residual cross-section at a notch

$\eta=e / d=$ proportional length of a notch

$\phi=0.9=$ resistance factor

\section{References}

American National Standards Institute (ANSI). 2004. Part 3: design provisions and equations. NDS Commentary, ANSI, Washington, D.C.: 22-23.

ANSI. 2012. National design specification for wood construction. ANSI/AWC NDS-2012, ANSI, Washington, D.C.

APA - The Engineered Wood Association (APA). 2010, Field notching and drilling of glued laminated timber beams. Technical Note EWS S560G, APA, Tacoma, Washington.

Asiz, A. and Smith I. 2008. Design of inclined glulam members with an end notch on the tension face, Paper 41-6-1, Working Commission W18, Conseil International du Bâtiment, Rotterdam, The Netherlands.

Canadian Standards Association (CSA). 1994. Engineering design in wood. CSA Standard 086-94, CSA, Ottawa, Ontario.

CSA. 2009. Engineering design in wood. CSA Standard 086-09, CSA, Ottawa, Ontario.

CSA. 2014. Engineering design in wood. CSA Standard 086-14, CSA, Ottawa, Ontario.

CSA. 2006. Structural glued-laminated timber. CSA Standard 0122-06, CSA, Toronto, Ontario.

Canadian Wood Council (CWC). 2010. Wood design manual. CWC, Ottawa, Ontario. 
Commite Europeen de Normalisation (CEN). 2004. Design of timber structures - Part 1-1: General Common rules and rules for buildings, Eurocode 5: Part 1-1, CEN, Brussels, Belgium.

DeGrace, R.F. 1986. Commentary on CSA Standard 086.1-M84 Engineering design in wood (limit states design), Special Publication 086.1.1-M1986. Canadian Standards Association, Toronto, Ontario.

Foliente, G. and McLain, T. 1992. Design of notched wood beams. Journal of Structural Engineering, 118(9): 2407-2420.

Gustafsson, P.J. 1988, A study of strength of notched beams. Paper 21-10-1, International Council for Building Research Studies and Documentation: Working Commission W18, Conseil International du Bâtiment,, Rotterdam, The Netherlands.

Jockwer, R. 2014. Structural behaviour of glued laminated timber beams with unreinforced and reinforced notches, Doctor of Science Thesis, Eidgenössische Technische Hochschule Zürich, Zurich, Switzerland.

Larsen, H.J. and P J Gustafsson, P.J. 1989. Design of end notched beams. Paper 22-10-1, Working Commission W18, Conseil International du Bâtiment, Rotterdam, The Netherlands.

Murphy, J. 1986. Strength and stiffness reduction of large notched beams. Journal of Structural Engineering, 112(9): 989-2000.

National Lumber Manufacturers Association (NLMA). 1944. National design specification for stress graded lumber and its fastenings. NLMA, Washington, D.C.

Riipola, K. 1990. Dimensioning of beams with cracks, notches and holes. an application of fracture mechanics. Paper 23-10-2, CIB-w18, CIB, Rotterdam, The Netherlands.

Smith, I. and Springer, G. 1993. Consideration of Gustafsson's proposed Eurocode 5 failure criterion for notched timber beams. Canadian Journal of Civil Engineering, 20(6): 1030-1036.

Smith, I., Chui, Y.H. and Hu, L.J. 1996. Reliability analysis for critical reaction forces of lumber members with an end notch. Canadian Journal of Civil Engineering, 23(1): 202-210.

Smith, I., Landis, E. and Gong, M. 2003. Fracture and fatigue in wood, John Wiley and Sons, Chichester, England. 
Smith, I., Snow, M., Asiz, A. and Vasic, S. 2007. Failure mechanisms in wood-based materials: Discrete, continuum, and hybrid finite element representations. A review, Holzforschung, 61(4): 352-359. van der Put, T.A.C.M. 1990. Tension perpendicular to grain at notches and joints. Paper 23-10-1, CIBw18, CIB, Rotterdam, The Netherlands.

Weckendorf, J., Meleki Kiwelu, H. and Smith, I. 2015. Critical reaction forces of glulam members with tension-side notches at end supports, Canadian Journal of Civil Engineering, in review.

Yeh, B. and Williamson, T.G. 2001. Evaluation of glulam shear strength using a full-size four-point test method, Working Commission 18 paper 34-12-2, International Council for Research and Innovation in Building and Construction, Rotterdam, The Netherlands.

Table 1. Notch factors in 2009 edition of CSA 086 (CSA 2009)

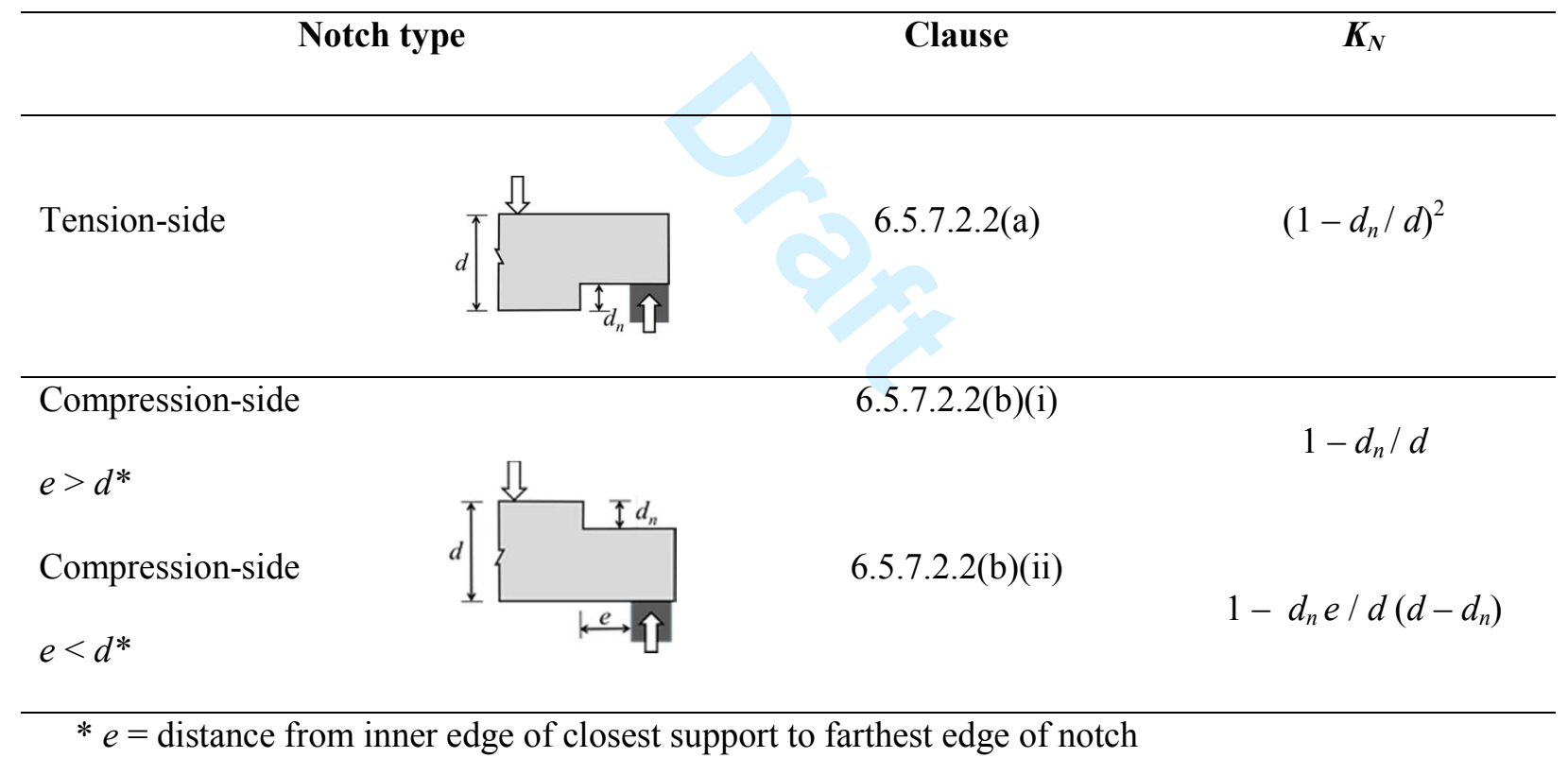


Table 2. Effects of neglecting presence of small notches for members with volumes $<2.0 \mathrm{~m}^{3}$

\section{Member dimensions:}

$b=80 \mathrm{~mm}, d=532 \mathrm{~mm}, d_{n}=53.2 \mathrm{~mm}(10 \%$ notch $), e=82.5 \mathrm{~mm}$, design volume $67.9 \times 10^{-3} \mathrm{~m}^{3}$

\section{Arrangement A, Figure 7(a):}

CSA 086-14 capacities: $\quad V_{r}$, clause 7.5.7.2(b) $\quad F_{r}$, clause 7.5.7.4.2 $\quad$ Total Factored Loading

$$
44.7 \mathrm{kN} \quad 51.6 \mathrm{kN} \text { (governs) } \quad W_{f}=81.6 \mathrm{kN}
$$

CSA 086-09 capacities:

$$
V_{r}, \text { clause 6.5.7.2.1(b) }
$$

notch free end notched end

$$
44.7 \mathrm{kN} \quad 36.6 \mathrm{kN} \text { (governs) } \quad W_{f}=77.2 \mathrm{kN}
$$

Ratio

CSA086-14 / CSA086-09

1.06

\section{Arrangement B, Figure 7(b):}

CSA 086-14 capacities: $\quad V_{r}$, clause 7.5.7.2(b) $\quad F_{r}$, clause 7.5.7.4.2

$$
44.7 \mathrm{kN} \text { (governs) } \quad 51.6 \mathrm{kN} \quad W_{f}=94.2 \mathrm{kN}
$$

CSA 086-09 capacities:

$$
V_{r} \text {, clause 6.5.7.2.1(b) }
$$

notch free end notched end
$44.7 \mathrm{kN}$
$36.6 \mathrm{kN}$ (governs)
$W_{f}=77.2 \mathrm{kN}$

Ratio

CSA086-14 / CSA086-09 
Table 3. Influence coefficients $C_{\text {notch-shape }}$ for members with volumes $<2.0 \mathrm{~m}^{3}\left(F_{r, 086-14} / V_{r, 086-09}=1.0\right.$ when $\alpha=0.9, \eta=0.2, b_{\text {eff }}=80 \mathrm{~mm}, d=1049 \mathrm{~mm}$ )

\begin{tabular}{lllllll}
\hline & \multicolumn{6}{c}{$\alpha=1-d_{n} / d$} \\
$\eta=e / d$ & 0.75 & 0.80 & 0.85 & 0.90 & 0.95 & 0.98 \\
\cline { 2 - 7 } 0.05 & 0.60 & 0.69 & 0.83 & 1.04 & 1.51 & 2.42 \\
0.10 & 0.59 & 0.69 & 0.82 & 1.03 & 1.50 & 2.41 \\
0.20 & 0.57 & 0.66 & 0.79 & 1.00 & 1.46 & 2.34 \\
0.40 & 0.51 & 0.59 & 0.71 & 0.90 & 1.32 & 2.13 \\
0.60 & 0.43 & 0.51 & 0.62 & 0.79 & 1.16 & 1.87 \\
0.80 & 0.37 & 0.44 & 0.53 & 0.68 & 1.01 & 1.63 \\
1.00 & 0.32 & 0.38 & 0.46 & 0.59 & 0.88 & 1.42 \\
1.50 & 0.23 & 0.28 & 0.34 & 0.44 & 0.65 & 1.05 \\
2.00 & 0.18 & 0.22 & 0.26 & 0.34 & 0.51 & 0.83 \\
\hline
\end{tabular}


Table 4. $C_{\text {notch-shape }}$ below which $F_{r, 086-14}$ is less than $V_{r, 086-09}$ for members with volumes $<2.0 \mathrm{~m}^{3}$

\begin{tabular}{|c|c|c|c|c|c|}
\hline \multirow[b]{2}{*}{$d(\mathrm{~mm})$} & \multicolumn{5}{|c|}{$b_{\text {eff }}(\mathrm{mm})$} \\
\hline & 20 & 80 & 130 & 175 & 215 \\
\hline 304 & 2.30 & 1.74 & 1.58 & 1.49 & 1.43 \\
\hline 608 & 1.73 & 1.31 & 1.19 & 1.12 & 1.08 \\
\hline 912 & 1.42 & 1.07 & 0.97 & 0.92 & 0.88 \\
\hline 1216 & 1.22 & 0.93 & 0.84 & 0.79 & 0.76 \\
\hline 1520 & 1.10 & 0.83 & 0.75 & 0.71 & 0.68 \\
\hline 1824 & 1.00 & 0.76 & 0.69 & 0.65 & 0.62 \\
\hline 2128 & 0.93 & 0.70 & 0.64 & 0.60 & 0.58 \\
\hline
\end{tabular}


Table 5. Impact of code changes on $W_{f}$ for single span members with uniform load

\begin{tabular}{|c|c|c|c|c|c|c|}
\hline a) Volume $Z=1.0 \mathrm{~m}^{3}, d_{n} / d=$ & $\overline{5, e / d}$ & 15, no & at on & oth e & & \\
\hline$d(\mathrm{~mm})$ & 228 & 456 & 684 & 912 & 1140 & 1140 \\
\hline$b_{e f f}(\mathrm{~mm})$ & 80 & 80 & 130 & 130 & 130 & 80 \\
\hline & & & $\operatorname{Max}$ & $W_{f}(1$ & & \\
\hline CSA 086-09:* & & & & & & \\
\hline$V_{r}=\phi F_{v} 0.48 A_{g} K_{N} C_{v} Z^{-0.18} \geq W_{f}$ & 36.8 & 73.5 & 179 & 239 & 299 & 184 \\
\hline CSA 086-14:** & & & & & & \\
\hline$W_{r}=\phi F_{v} 0.48 A_{g} C_{v} Z^{0.18} \geq W_{f}$ & $\underline{50.9}$ & 102 & 248 & 331 & 414 & 255 \\
\hline $2 V_{r}\left(V_{r}=\phi F_{v} A_{n}\right)$ & 57.5 & 115 & 279 & 374 & 466 & 345 \\
\hline $2 F_{r}\left(F_{r}=\phi F_{f} A_{g} K_{N}\right)$ & 53.6 & $\underline{75.8}$ & $\underline{137}$ & $\underline{158}$ & $\underline{177}$ & $\underline{120}$ \\
\hline Min. $W_{r}, 2 V_{r}, 2 F_{r}$ & 50.9 & 75.8 & 137 & 158 & 177 & 120 \\
\hline Ratio: CSA 086-14 / CSA 086-09 & 1.38 & 1.03 & 0.77 & 0.66 & 0.59 & 0.65 \\
\hline b) $\quad$ Volume $Z=3.0 \mathrm{~m}^{3}, d_{n}$ & $\mathbf{0 . 1 5}$ & $=0.15$ & $\operatorname{tch}$ at & or bo & & \\
\hline$d(\mathrm{~mm})$ & 228 & 456 & 684 & 912 & 1140 & 1368 \\
\hline$b_{e f f}(\mathrm{~mm})$ & 80 & 80 & 130 & 130 & 130 & 130 \\
\hline
\end{tabular}

Maximum $W_{f}(\mathrm{kN})$

\section{CSA 086-09:*}

\begin{tabular}{ll|l|l|l|l|l}
$V_{r}=\phi F_{v} 0.48 A_{g} K_{N} C_{v} Z^{-0.18} \geq W_{f}$ & 30.2 & 60.3 & 147 & 196 & 245 & 295
\end{tabular}

\section{CSA 086-14:**}

$W_{r}=\phi F_{v} 0.48 A_{g} C_{v} Z^{-0.18} \geq W_{f}$

\begin{tabular}{llllll}
\hline 50.9 & 102 & 248 & 331 & 414 & 469
\end{tabular}

$2 V_{r}\left(V_{r}=\phi F_{v} A_{n}\right)$

\begin{tabular}{l|l|l|l|l|l}
57.5 & 113 & 279 & 373 & 466 & 560
\end{tabular}

$2 F_{r}\left(F_{r}=\phi F_{f} A_{g} K_{N}\right)$

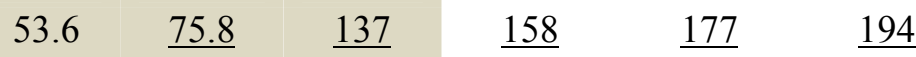

Min. $W_{r}, 2 V_{r}, 2 F_{r}$

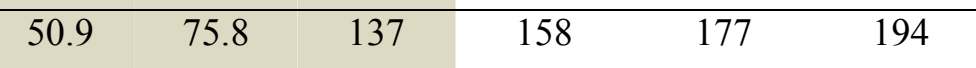




\begin{tabular}{|c|c|c|c|c|c|c|}
\hline Ratio: CSA 086-14 / CSA 086-09 & 1.69 & 1.26 & 0.93 & 0.81 & 0.72 & 0.66 \\
\hline \multicolumn{7}{|c|}{ c) Volume $Z=5.0 \mathrm{~m}^{3}, d_{n} / d=0.15, e / d=0.15$, notch at one or both ends } \\
\hline$d(\mathrm{~mm})$ & 228 & 456 & 684 & 912 & 1140 & 1368 \\
\hline$b_{e f f}(\mathrm{~mm})$ & 80 & 80 & 130 & 130 & 130 & 130 \\
\hline
\end{tabular}

\section{CSA 086-09:*}

$V_{r}=\phi F_{v} 0.48 A_{g} K_{N} C_{v} Z^{-0.18} \geq W_{f}$

134

179

224

269

\section{CSA 086-14:**}

$W_{r}=\phi F_{v} 0.48 A_{g} C_{v} Z^{0.18} \geq W_{f}$

$\underline{50.9} \quad 102$

248

331

414

496

$2 V_{r}\left(V_{r}=\phi F_{v} A_{n}\right)$

$$
57.5
$$

113

279

373

466

560

$2 F_{r}\left(F_{r}=\phi F_{f} A_{g} K_{N}\right)$

$53.6 \quad \underline{75.8}$

$\underline{137}$

$\underline{158}$

$\underline{177}$

194

Min. $W_{r}, 2 V_{r}, 2 F_{r}$

50.9

50.9

75.8

137

158

177

194

\section{Ratio: CSA 086-14 / CSA 086-09}

1.85

1.38

1.02

0.88

0.79

0.72 
Table 6. Impact of code changes on $W_{f}$ for single span members with triangular load

\begin{tabular}{|lcccccc|}
\hline Volume $\boldsymbol{Z}=\mathbf{3 . 0} \mathbf{~ m}^{3}, \boldsymbol{d}_{\boldsymbol{n}} / \boldsymbol{d}=\mathbf{0 . 1 5}, \boldsymbol{e} / \boldsymbol{d}=\mathbf{0 . 1 5}$, notch at one end & & & & \\
$d(\mathrm{~mm})$ & 228 & 456 & 684 & 912 & 1140 & 1368 \\
$b_{\text {eff }}(\mathrm{mm})$ & 80 & 80 & 130 & 130 & 130 & 130 \\
\hline
\end{tabular}

Maximum $W_{f}(\mathrm{kN})$

\begin{tabular}{|c|c|c|c|c|c|c|}
\hline CSA 086-09:* & & & & & & \\
\hline$V_{r}=\phi F_{v} 0.48 A_{g} K_{N} C_{v} Z^{0.18} \geq W_{f}$ & 27.8 & 55.6 & 135 & 191 & 226 & 272 \\
\hline CSA 086-14:** & & & & & & \\
\hline$W_{r}=\phi F_{v} 0.48 A_{g} C_{v} Z^{0.18} \geq W_{f}$ & $\underline{46.9}$ & 94.0 & 228 & 305 & 381 & 460 \\
\hline i) Notch at peak load end & & & & & & \\
\hline $2 V_{r}\left(V_{r}=\phi F_{v} A_{n}\right)$ & 57.5 & 115 & 279 & 374 & 466 & 560 \\
\hline ii) Notch at peak load end & & & & & & \\
\hline $3 V_{r}\left(V_{r}=\phi F_{v} A_{n}\right)$ & 86.2 & 173 & 419 & 561 & 699 & 840 \\
\hline i) Notch at peak load end & & & & & & \\
\hline $2 F_{r}\left(F_{r}=\phi F_{f} A_{g} K_{N}\right)$ & 53.6 & $\underline{75.8}$ & $\underline{137}$ & $\underline{158}$ & $\underline{177}$ & $\underline{194}$ \\
\hline ii) Notch at zero load end & & & & & & \\
\hline $3 F_{r}\left(F_{r}=\phi F_{f} A_{g} K_{N}\right)$ & 80.4 & $\underline{114}$ & $\underline{206}$ & $\underline{237}$ & $\underline{266}$ & $\underline{291}$ \\
\hline Min. $W_{r}, V_{r}, F_{r}$ & & & & & & \\
\hline Notch at peak load end & 46.9 & 75.8 & 137 & 158 & 177 & 194 \\
\hline Notch at zero load end) & 46.9 & 114 & 206 & 237 & 266 & 291 \\
\hline Ratio: CSA 086-14 / CSA 086-09 & & & & & & \\
\hline Notch at peak load end & 1.69 & 1.36 & 1.01 & 0.827 & 0.78 & 0.71 \\
\hline Notch at zero load end) & 1.69 & 2.05 & 1.52 & 1.24 & 1.17 & 1.07 \\
\hline
\end{tabular}


** $K_{N}=\left[0.006 d\left\{1.6(1 / \alpha-1)+\eta^{2}\left(1 / \alpha^{3}-1\right)\right\}\right]^{-1 / 2}$ 
Table 7. Impact of code changes on $W_{f}$ for symmetrical double span members with uniform

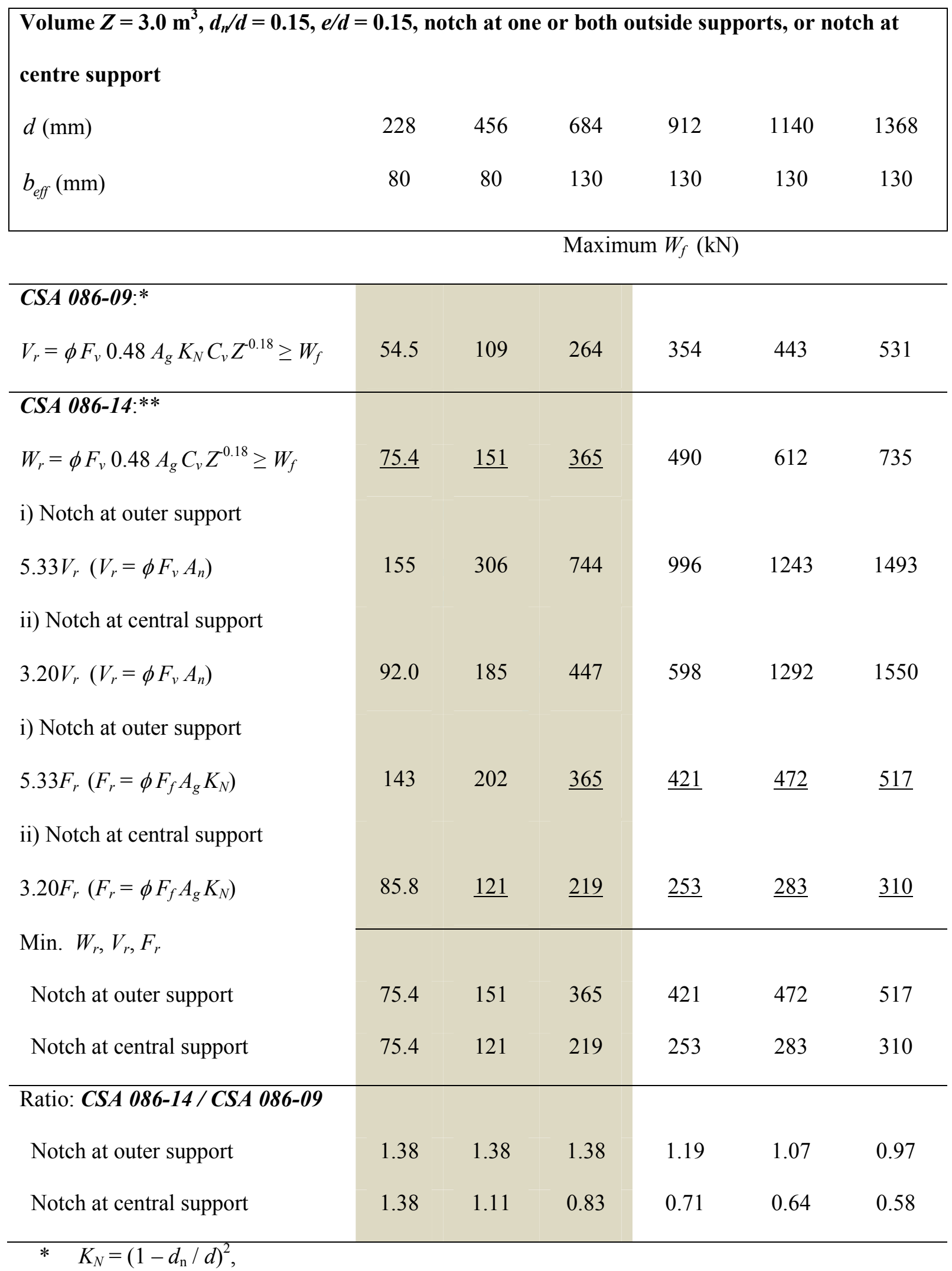


** $K_{N}=\left[0.006 d\left\{1.6(1 / \alpha-1)+\eta^{2}\left(1 / \alpha^{3}-1\right)\right\}\right]^{-1 / 2}$ 


\section{LIST OF FIGURES}

Figure 1. Example of cracking and von Mises stress concentration caused by a notch

Figure 2. Example of shear stress distributions presumed to exist in a glulam member by pre 2014 design provisions

Figure 3. Actual failure mechanisms associated with notch induced cracking

Figure 4. Tension-side notch arrangements covered by sawn lumber design provisions

Figure 5. Logic of dual factored shear resistance calculations applicable to sawn lumber members

Figure 6. Example of disruption of stress fields for members with short and long notches of limited depth

Figure 7. Configurations of notched glulam members illustrating consideration or neglect of effects of loads close to supports

Figure 8. Multiplicative influence coefficients applicable to ratio $F_{r, 086-14} / V_{r, 086-09}$ for members with volumes $<2.0 \mathrm{~m}^{3}\left(F_{r, 086-14} / V_{r, 086-09}=1.0\right.$ when $\left.\alpha=0.9, \eta=0.2, b_{\text {eff }}=80 \mathrm{~mm}, d=1049 \mathrm{~mm}\right)$ 


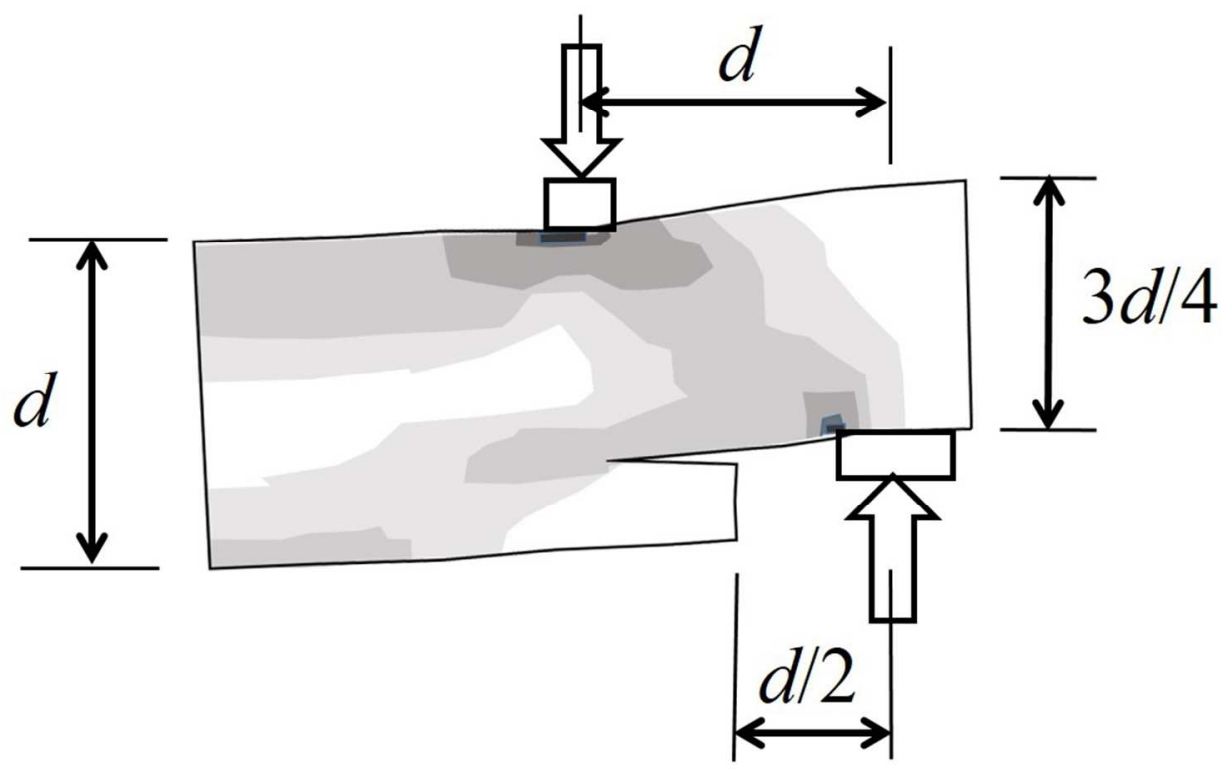

$187 \times 113 \mathrm{~mm}(150 \times 150 \mathrm{DPI})$ 


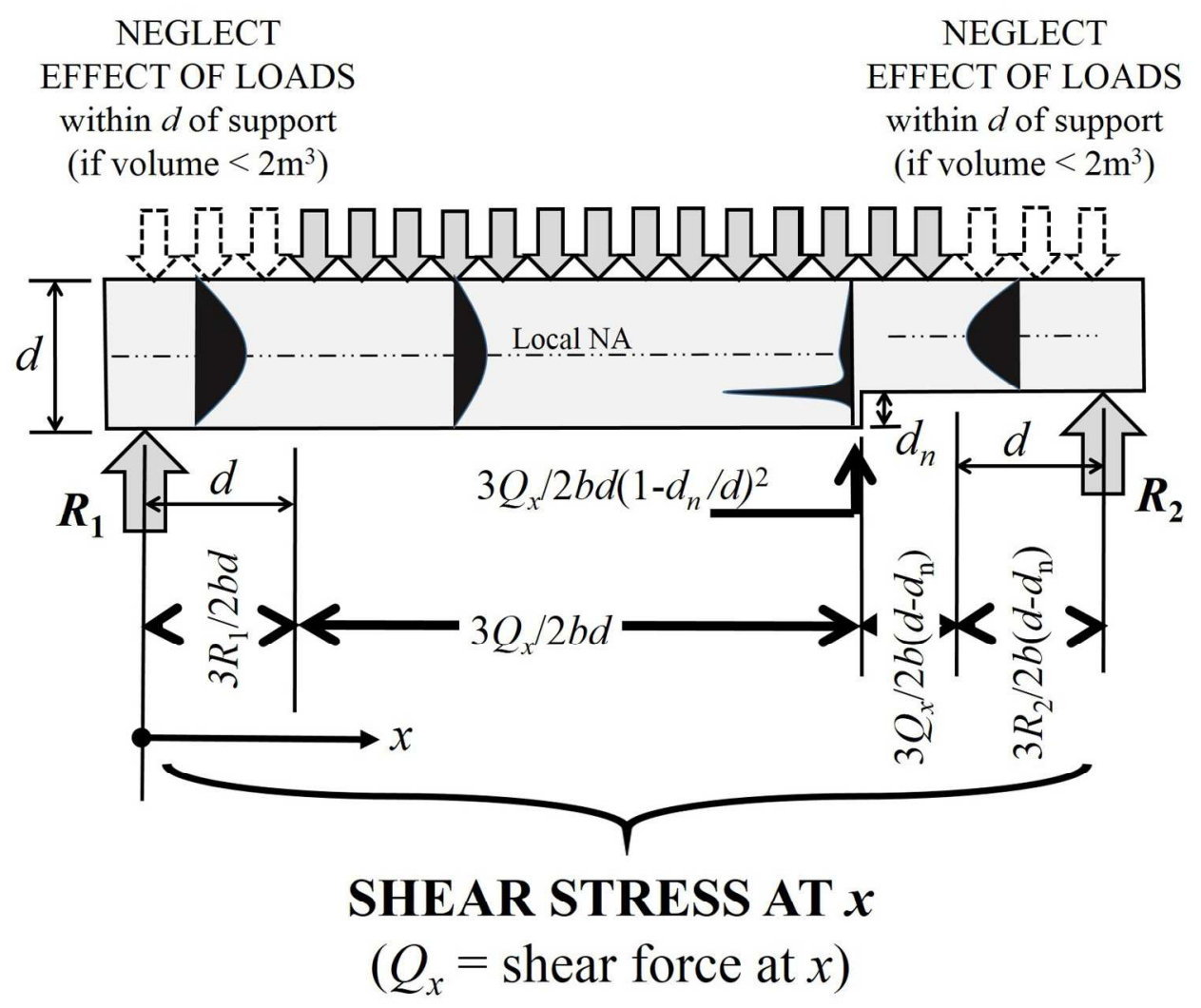

$288 \times 239 m m(150 \times 150$ DPI $)$ 


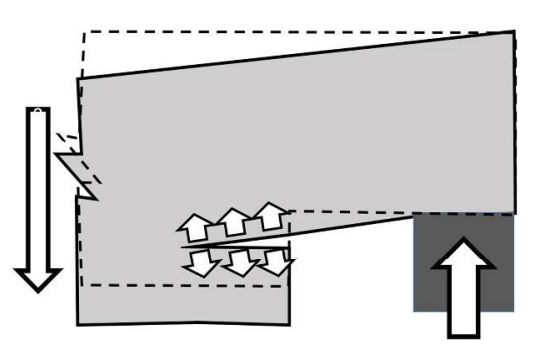

(a) Opening mode (Mode I)

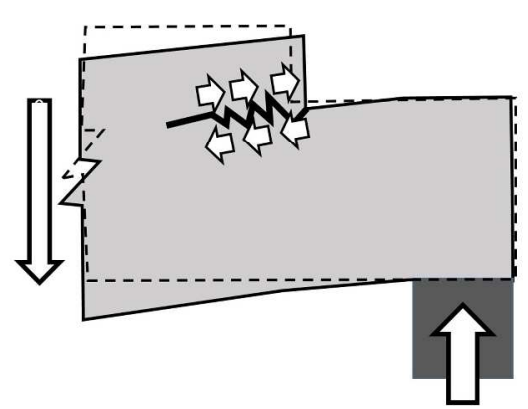

(b) Forward shearing mode (Mode II)

$429 \times 155 \mathrm{~mm}(150 \times 150 \mathrm{DPI})$ 


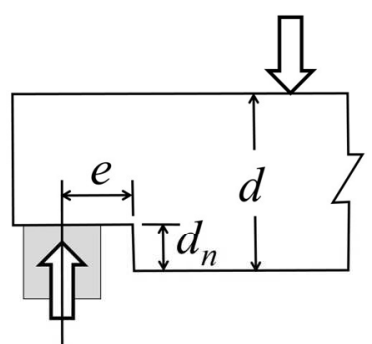

(a) Flat member with square notch face

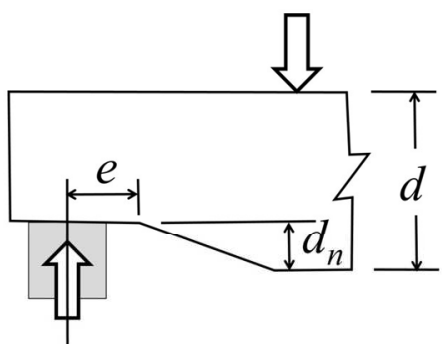

(b) Flat member with inclined notch face

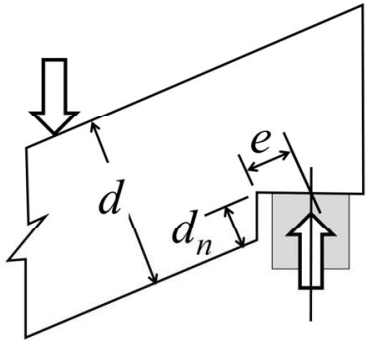

(c) Inclined member with bird-mouth notch

$307 \times 106 \mathrm{~mm}(150 \times 150 \mathrm{DPI})$ 


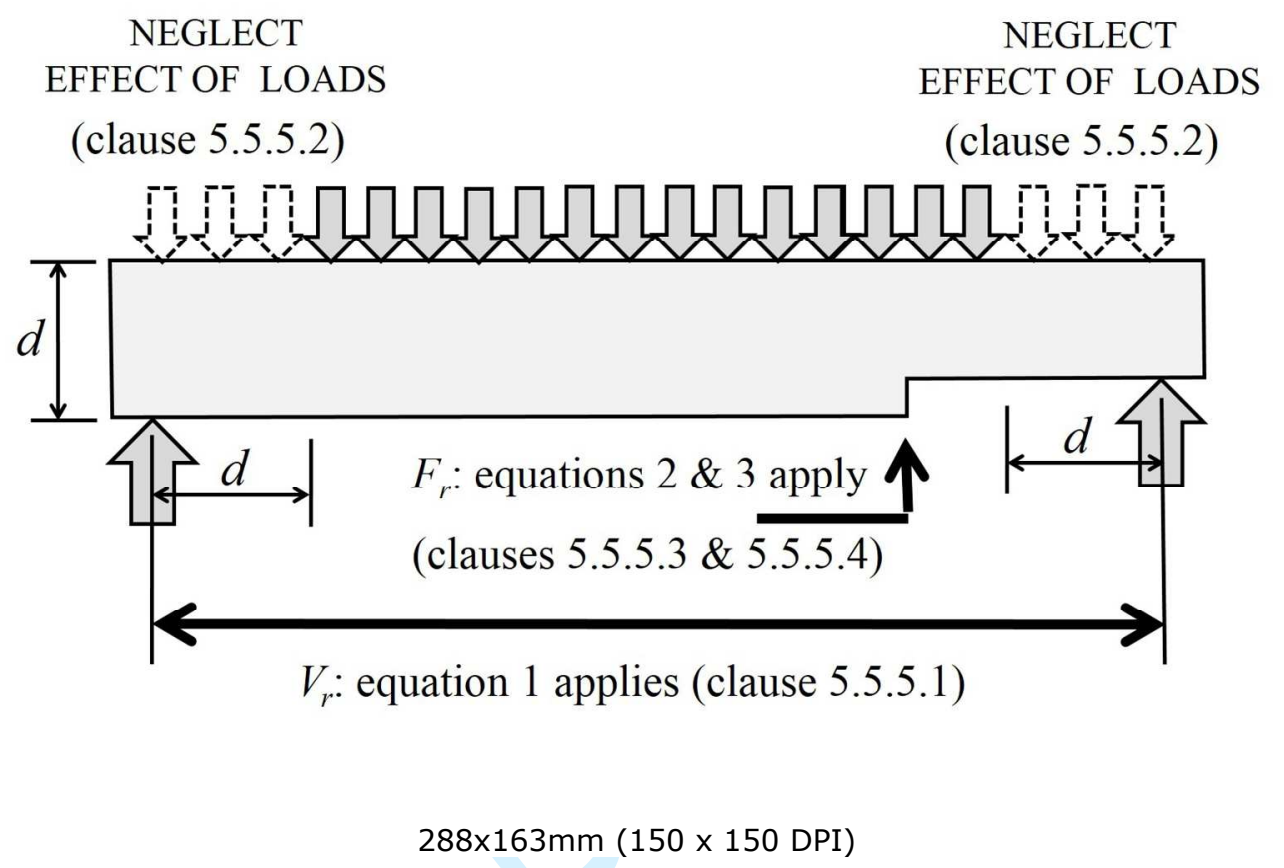




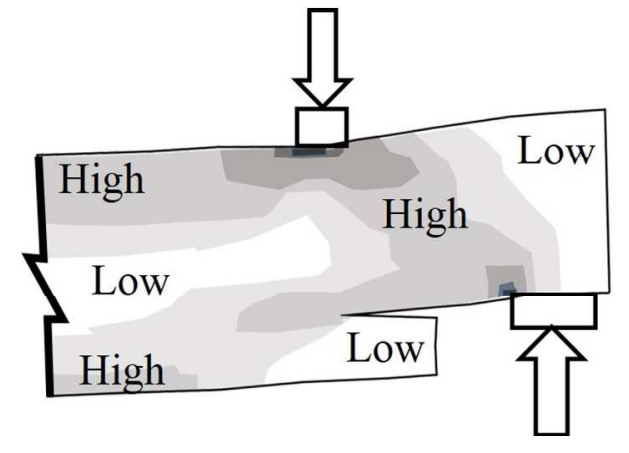

(a) von Mises

stresses: short notch

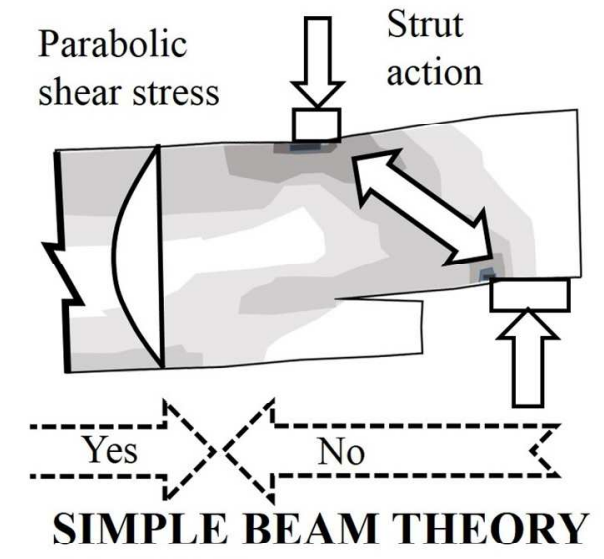

APPLIES

(b) Applicability of simple beam theory: short notch

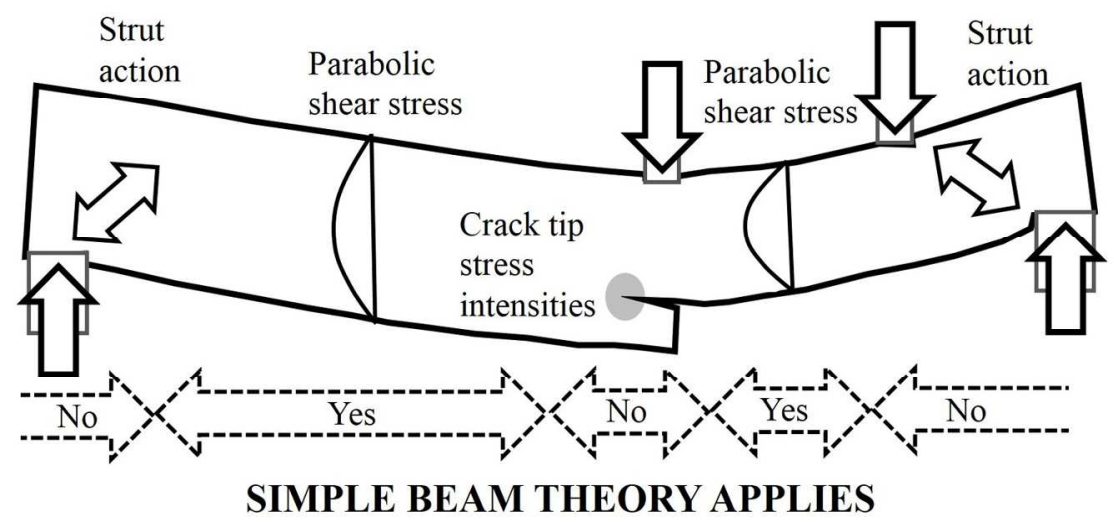

(c) Applicability of simple beam theory: long notch 


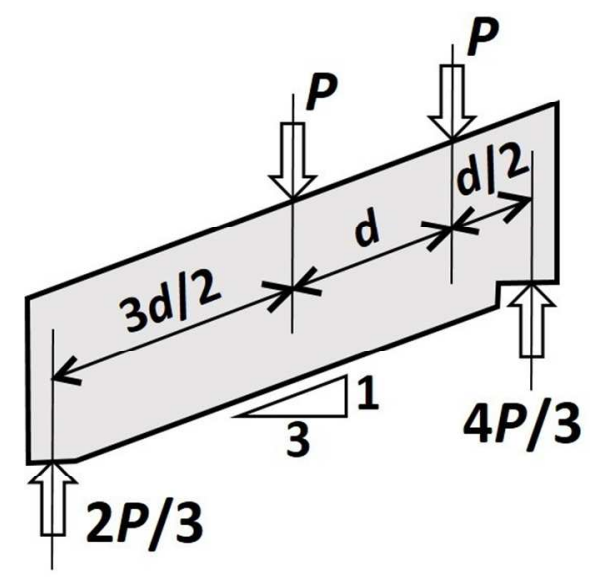

(a) Arrangement A

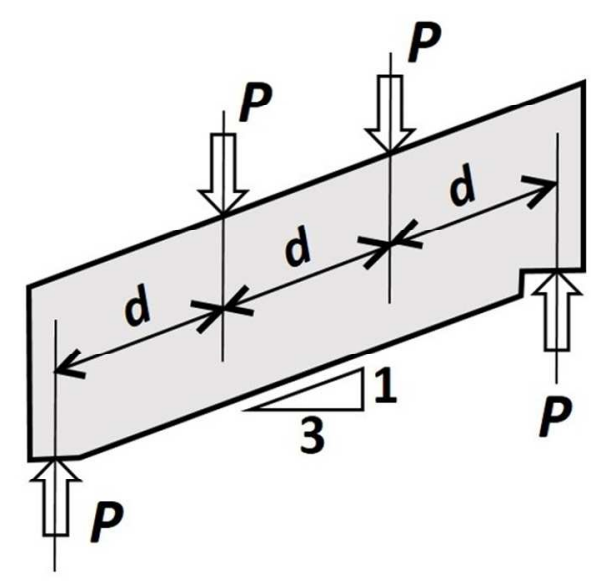

(b) Arrangement B

$210 \times 120 \mathrm{~mm}(150 \times 150 \mathrm{DPI})$ 


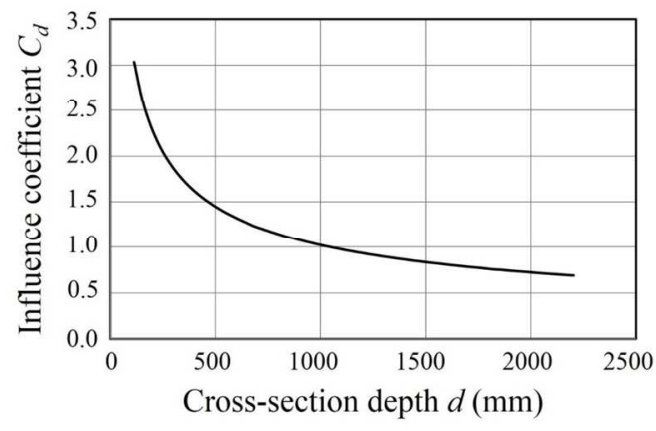

(a) $C_{d}$ - effect of varying $d$

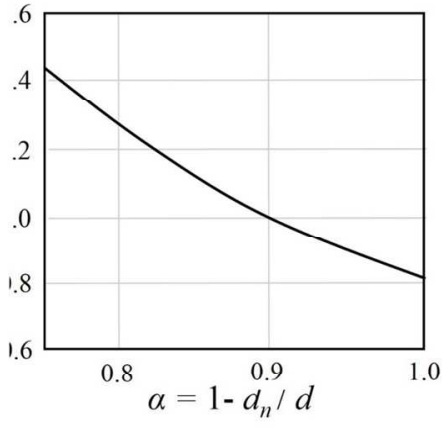

(b) $C_{\alpha}$ - effect of varying $\alpha$

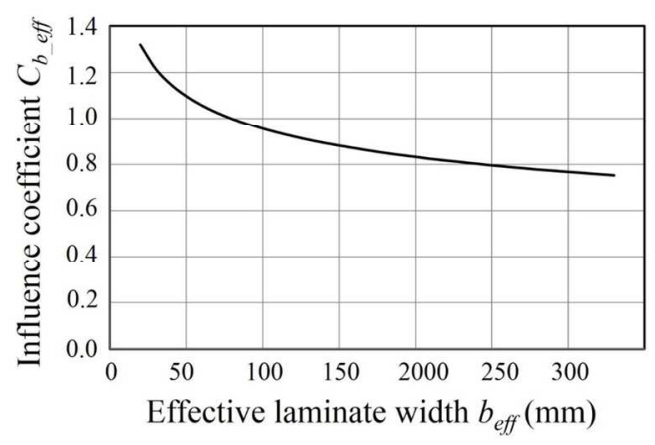

(c) $C_{b_{-} \text {eff }}$ - effect of varying $b_{\text {eff }}$

$275 \times 231 \mathrm{~mm}(150 \times 150 \mathrm{DPI})$ 